\title{
HOW TO CONVERT BIOLOGICAL CARBON INTO GRAPHITE FOR AMS
}

\author{
Girma Getachew ${ }^{1}$ Seung-Hyun Kim ${ }^{1} \bullet$ Betty J Burri $^{2} \bullet$ Peter B Kelly ${ }^{3}$ Kurt W Haack ${ }^{4}$ \\ Ted J Ognibene ${ }^{4} \bullet$ Bruce A Buchholz $^{4} \bullet \mathrm{John} \mathrm{S} \mathrm{Vogel}^{4} \bullet$ Jonathan Modrow $^{1} \bullet$ Andrew J Clifford ${ }^{1,5}$
}

ABSTRACT. Isotope tracer studies, particularly radiocarbon measurements, play a key role in biological, nutritional, and environmental research. Accelerator mass spectrometry (AMS) is now the most sensitive detection method for ${ }^{14} \mathrm{C}$, but AMS is not widely used in kinetic studies of humans. Part of the reason is the expense, but costs would decrease if AMS were used more widely. One component in the cost is sample preparation for AMS. Biological and environmental samples are commonly reduced to graphite before they are analyzed by AMS. Improvements and mechanization of this multistep procedure is slowed by a lack of organized educational materials for AMS sample preparation that would allow new investigators to work with the technique without a substantial outlay of time and effort. We present a detailed sample preparation protocol for graphitizing biological samples for AMS and include examples of nutrition studies that have used this procedure.

\section{INTRODUCTION}

Accelerator mass spectrometry (AMS) is the most sensitive radioisotope detection method and has the lowest quantification limits of currently available measurement techniques. It is a fundamental tool in archeology, oceanography, and geosciences due to this high sensitivity (Kutschera 2005). AMS is suitable for the biological sciences because AMS studies can use doses of radioisotopes that cause minimal radiation exposures that are below safety thresholds, so that they can be used in a greater variety of human studies. There are also fewer waste disposal problems than traditional radioisotope methods. Furthermore, the low dose and specific activity can greatly reduce costs.

Although $90 \%$ of all AMS measurements worldwide are devoted to radiocarbon, its value for applications in biological and clinical studies is less well appreciated. Isotope labels provide chemically exact analogues of almost any compound, so AMS is suitable for studies of the absorption, distribution, metabolism, and excretion of pharmaceutical compounds. Radioactive drug candidates can trace metabolic intermediates, macromolecular adducts, or receptor/ligand interactions. In nutrition studies, tracer methods enable scientists to directly determine the fate of a labeled nutrient from digestion and absorption through metabolism and excretion in human subjects. Since AMS is an isotope ratio measurement, the results provide a tissue concentration for the traced compound, greatly simplifying experimental protocols.

Despite these advantages, AMS is rarely used in nutritional studies. A major reason for the slow adoption by the biological sciences is that AMS sample preparation is still a complex laboratory procedure. Biological samples are usually converted to graphite before they are analyzed. This is a 2step process. The first step oxidizes solid or liquid tissue carbon to $\mathrm{CO}_{2}$ gas. The second step reduces the $\mathrm{CO}_{2}$ gas to graphite that is analyzed for ${ }^{14} \mathrm{C}$ by AMS. Clear, detailed protocols describing AMS sample preparation for investigators new to AMS would help its use. The objective of this paper is to present a detailed sample preparation procedure for converting biological carbon (urine, feces, tissue, and blood samples) to graphite for AMS.

\footnotetext{
${ }^{1}$ Department of Nutrition, University of California, Davis, California 95616, USA. ${ }^{2}$ USDA, Western Human Nutrition Research Center, Davis, California 95616, USA. ${ }^{3}$ Department of Chemistry, University of California, Davis, California 95616, USA. ${ }^{4}$ Lawrence Livermore National Laboratory, Livermore, California 94550, USA.

${ }^{5}$ Corresponding author. Email: ajclifford@ucdavis.edu.
} 


\section{MATERIALS AND METHODS}

\section{Materials}

An itemized list of equipment, chemicals, and other supplies used by our group for graphite preparation is given in Table 1. Materials can be obtained from suppliers other than those listed in Table 1. Plans for the construction of "custom-made" items are available from the corresponding author. Special AMS sample holders for graphitized samples are ion-source specific and are provided by the AMS laboratory.

\section{Material-Cleaning Procedures}

The 6-mm quartz sample tubes ( $4 \mathrm{~mm} \mathrm{ID} \times 6 \mathrm{~mm}$ OD $\times 38 \mathrm{~mm} \mathrm{~L}$ ) for biological samples and the 9$\mathrm{mm}$ break-end quartz combustion tubes $\left(7 \mathrm{~mm} \mathrm{ID} \times 9 \mathrm{~mm} \mathrm{OD} \times 18 \mathrm{~cm} \mathrm{~L}\right.$ ) are heated at $900{ }^{\circ} \mathrm{C}$ in air for $2.5 \mathrm{hr}$ prior to use to remove organic contaminants. The 6-mm borosilicate glass (Pyrex ${ }^{\circledR}$, Kimax, or other generic borosilicate glass) sample tubes $(6 \mathrm{~mm} \mathrm{OD} \times 50 \mathrm{~mm} \mathrm{~L})$ for high-performance liquid chromatography (HPLC) fractions are heated in air at $500{ }^{\circ} \mathrm{C}$ for $2 \mathrm{hr}$ to remove organic contaminants. Copper (II) oxide (CuO) reagent wire (Sigma-Aldrich 31,043-3) is also heated in air at $500{ }^{\circ} \mathrm{C}$ for $2 \mathrm{hr}$ to remove organic contaminants including adsorbed copper carbonate. The iron powder (Sigma-Aldrich 25,563-7) must be kept well sealed between usages to minimize atmospheric contamination. The same is true for the zinc dust (Sigma-Aldrich 20,998-8).

\section{Sample Collection}

All sample collection and preparation should adhere to procedures that are known to minimize contaminations of samples from inadvertent movement of normally undetectable isotope concentrations in the laboratory (Buchholz et al. 2000). For human in vivo studies, the subject is orally or intravenously administered a small tracer dose $(1-100 \mathrm{nCi})$ of a ${ }^{14} \mathrm{C}$-labeled micronutrient, food component, or pharmaceutical. Tissues (such as blood, feces, urine, saliva, skin, needle biopsies, or breath) are sampled as a function of time since dosing and then stored at $-80^{\circ} \mathrm{C}$ in glass or suitable plastic vials and bottles until preparation for analysis. Refrigeration to $-20^{\circ} \mathrm{C}$ is acceptable if the samples will be stored for only a few days and if all of the traced compounds and metabolites are stable and non-volatile. Indwelling catheters are used for collecting frequent small blood samples that reflect absorption kinetics shortly after dosing.

\section{Sample Drying}

After thawing a stored biological sample (or directly after collecting a fresh sample), small aliquots ( $20 \mu \mathrm{L}$ plasma, $100 \mu \mathrm{L}$ urine, $5 \mathrm{mg}$ wet tissue, $75 \mu \mathrm{L}$ homogenized feces, etc.) containing $0.5-2 \mathrm{mg}$ of carbon (Vogel and Love 2005) are first placed into a 6-mm quartz sample tube (Table 1). HPLC fractions are automatically collected into 6- $\mathrm{mm}$ borosilicate tubes. The 6-mm quartz or borosilicate sample tube is then nested inside a second 10-mm borosilicate glass culture tube (Pyrex, Kimax, or other generic borosilicate glass, $10 \mathrm{~mm} \mathrm{OD} \times 75 \mathrm{~mm} \mathrm{~L}$ ) that is further nested inside a third $13-\mathrm{mm}$ borosilicate glass culture tube (Pyrex, Kimax, or other generic borosilicate glass, $13 \mathrm{~mm}$ OD $\times 100$ $\mathrm{mm} \mathrm{L}$ ) that is nested inside a fourth $15-\mathrm{mL}$ Falcon tube, which fits into a centrifugal evaporator (Figure 1A). The biological samples are then evaporated to dryness, and the Falcon tube is capped promptly and stored.

This nesting is necessary for lack of a suitable rotor for our evaporator, and some nesting facilitates handling and avoids touching and contaminating the exterior of the 6-mm quartz or borosilicate sample tube. Careful maintenance of the vacuum system minimizes the time needed to dry the samples, and this in turn can minimize inter-sample contamination with aerosols from the vacuum. 
Table 1 Equipment, chemicals, and other supplies used in graphite preparation.

\begin{tabular}{|c|c|c|}
\hline Item description & Supplier & Catalog \# \\
\hline \multicolumn{3}{|l|}{ Sample processing } \\
\hline Jouan RC 10.10 & Jouan Inc. & \\
\hline Vacuum concentrator & Winchester, Virginia, USA & \\
\hline Unijet II refrigerated aspirator & Uniequip, Munich, Germany & \\
\hline $\begin{array}{l}\text { Borosilicate glass }\left(\text { Pyrex }^{\circledR}, \text { Kimax, }\right. \\
\text { or other generic borosilicate glass, } \\
6 \mathrm{~mm} \mathrm{OD} \times 50 \mathrm{~mm} \mathrm{~L} \text { ) }\end{array}$ & $\begin{array}{l}\text { Kimble Glass Inc. } \\
\text { Vineland, New Jersey, USA }\end{array}$ & $45060-650$ \\
\hline $\begin{array}{l}\text { Borosilicate glass culture tube } \\
\text { (Pyrex, Kimax, or other generic boro- } \\
\text { silicate glass, } 10 \mathrm{~mm} \mathrm{OD} \times 75 \mathrm{~mm} \mathrm{~L} \text { ) }\end{array}$ & $\begin{array}{l}\text { Fisher Scientific Inc. } \\
\text { Allentown, Pennsylvania, USA }\end{array}$ & $16-961-25$ \\
\hline $\begin{array}{l}\text { Borosilicate glass culture tube (Pyrex, } \\
\text { Kimax, or other generic borosilicate } \\
\text { glass, } 13 \mathrm{~mm} \mathrm{OD} \times 100 \mathrm{~mm} \mathrm{~L} \text { ) }\end{array}$ & Fisher Scientific Inc. & $16-961-27$ \\
\hline $\begin{array}{l}\text { Quartz sample tube ( } 4 \mathrm{~mm} \mathrm{ID} \times 6 \mathrm{~mm} \\
\mathrm{OD} \times 38 \mathrm{~mm} \mathrm{~L}, \mathrm{CFQ})\end{array}$ & $\begin{array}{l}\text { Custom-made of quartz tubing from GM } \\
\text { Associates, Oakland, California, USA; or } \\
\text { tubes from Scientific Glass International, } \\
\text { Sanford, Florida, USA }\end{array}$ & $\begin{array}{l}\text { Tubing \# } \\
6000-8\end{array}$ \\
\hline Falcon tube $(15 \mathrm{~mL})$ & $\begin{array}{l}\text { Becton Dickinson Labware, Franklin } \\
\text { Lakes, New Jersey, USA }\end{array}$ & \\
\hline Porcelain evaporating dish & $\begin{array}{l}\text { VWR International, Brisbane, } \\
\text { California, USA }\end{array}$ & $25310-256$ \\
\hline Tributyrin & MP Biomedical, Solon, Ohio, USA & 103111 \\
\hline ANU sugar standards & Australian National University & \\
\hline
\end{tabular}

\section{Combustion}

\begin{tabular}{|c|c|c|}
\hline $\begin{array}{l}\text { Break-end quartz combustion tube } \\
(7 \mathrm{~mm} \mathrm{ID} \times 9 \mathrm{~mm} \mathrm{OD} \times 18 \mathrm{~cm} \mathrm{~L}, \mathrm{CFQ})\end{array}$ & $\begin{array}{l}\text { Custom-made of quartz tubing from GM } \\
\text { Associates; or tubes from Scientific } \\
\text { Glass International }\end{array}$ & $\begin{array}{l}\text { Tubing \# } \\
6000-14\end{array}$ \\
\hline Vacuum pump (turbo-V70) & Varian, Palo Alto, California, USA & \\
\hline 316 vacuum gauge controller & $\begin{array}{l}\text { Granville-Phillips, Longmont, Colorado, } \\
\text { USA }\end{array}$ & \\
\hline Convectron gauge (pressure sensor) & $\begin{array}{l}\text { Helix Technology, Longmont, Colorado, } \\
\text { USA }\end{array}$ & 275071 \\
\hline Copper reagent, granular, $99.90+\%$ & Sigma-Aldrich, St. Louis, Missouri, USA & $31,140-5$ \\
\hline $\begin{array}{l}\text { Copper (II) oxide reagent, } \\
\text { mixture of } \mathrm{CuO} \text { and } \mathrm{Cu}_{2} \mathrm{O} \text {, wire }\end{array}$ & Sigma-Aldrich & $31,043-3$ \\
\hline $\begin{array}{l}\text { Vulcan box furnace with } \\
\text { programmable controls }\end{array}$ & $\begin{array}{l}\text { DENTSPLY, Burlington, New Jersey, } \\
\text { USA }\end{array}$ & \\
\hline Magazine & $\begin{array}{l}\text { Custom-made, plans available from } \\
\text { corresponding author }\end{array}$ & \\
\hline
\end{tabular}

Gas transfer

\begin{tabular}{lll}
\hline Iron powder, $99.99+\%$ & Sigma-Aldrich & $25,563-7$ \\
\hline Zinc, dust, $<10$ micron, $98+\%$ & Sigma-Aldrich & $20,998-8$ \\
\hline Laboratory jack & Fisher Scientific Inc. & $14-673-50$ \\
\hline
\end{tabular}


Table 1 Equipment, chemicals, and other supplies used in graphite preparation. (Continued)

\begin{tabular}{lll}
\hline Item description & Supplier & Catalog \# \\
\hline Dewar shielded vacuum flask & VWR International & $63422-028$ \\
\hline $\begin{array}{l}\text { Septa-sealed vials (Pyrex, Kimax, } \\
\text { or other generic borosilicate glass, } \\
8.0 \text { mm OD } \times 80 \text { mm L) }\end{array}$ & $\begin{array}{l}\text { Kimax, custom-made by Kimble } \\
\text { Kontes Scientific Glassware, } \\
\text { Vineland, New Jersey, USA }\end{array}$ & \\
\hline $\begin{array}{l}\text { Septa-sealed inner vials (Pyrex, } \\
\text { Kimax, or other generic borosilicate } \\
\text { glass, 3.0 mm ID } \times 3.7 \text { mm OD } \times\end{array}$ & $\begin{array}{l}\text { Pyrex, Scientific Instruments Service, } \\
\text { Inc., Ringoes, New Jersey, USA }\end{array}$ & GSV500 \\
$\begin{array}{l}\text { 30 mm L) } \\
\begin{array}{l}\text { Pyrex beads (Pyrex, Kimax, } \\
\text { or other generic borosilicate glass, }\end{array}\end{array}$ & VWR & \\
\hline mm diameter) & & $26396-803$ \\
\hline N-mm crimp seal, TEF/SIL & Fisher Scientific Inc. & $69008-4 A$ \\
\hline Nalgene tubing (5/16" ID $\times 1 / 2 "$ OD) & VWR & $632013-506$ \\
\hline BD single use 26-G" needles & Fisher Scientific Inc. & $14-826-10$ \\
\hline Stopcocks (4-way stopcocks) & Qosina, Edgewood, New York, USA & 99701 \\
\hline Male luers & Qosina & 64014
\end{tabular}

Reducing $\mathrm{CO}_{2}$ to graphite

Heating block with 60-tube capacity Custom-made, plans available from corresponding author

\section{Loading graphite into the AMS sample holder}

\begin{tabular}{lll} 
Plexiglas $^{\circledR}$ box & $\begin{array}{l}\text { Custom-made, plans available from } \\
\text { corresponding author }\end{array}$ & \\
\hline $\begin{array}{l}\text { \#55 gauge drill blanks (Morse, Ver- } \\
\text { mont Drill, or any other manufacturer) }\end{array}$ & $\begin{array}{l}\text { Morse Cutting Tools, Madison Heights, } \\
\text { Michigan, USA; Vermont American, } \\
\text { Mount Prospect, Illinois, USA }\end{array}$ & \\
\hline AMS sample holders & $\begin{array}{l}\text { LLNL, Livermore, California, USA } \\
\text { Anvil }\end{array}$ & $\begin{array}{l}\text { Custom-made, plans available from } \\
\text { corresponding author }\end{array}$ \\
\hline Vacuum (Wet/Dry Vac) & $\begin{array}{l}\text { Shop-Vac Corporation, Williamsport, } \\
\text { Pennsylvania, USA }\end{array}$ & Model 2010 \\
Hammer & 3-kg weight & \\
\hline
\end{tabular}

\section{Transfer of Samples to Combustion Tubes}

After each biological sample is evaporated to dryness, only the 6-mm quartz or borosilicate sample tube is carefully removed using a single surface-use disposable wipe; a small amount of copper (II) oxide reagent wire $(\sim 40 \mathrm{mg})$ is added, and all nesting tubes are discarded. Nitrogen-rich biological samples, such as urine, may require a small amount of added elemental copper reagent $(10-20 \mathrm{mg})$ (Sigma-Aldrich 31,140-5) to insure that nitrogen oxides produced in combustion are reduced to $\mathrm{N}_{2}$. The 6-mm quartz or borosilicate sample tube is placed in the 9-mm break-end quartz combustion tube (Table 1). The 9-mm break-end quartz combustion tube, loaded with the 6-mm quartz or borosilicate sample tube containing copper (II) oxide reagent wire (and elemental copper as needed for nitrogen rich biological samples), is gently pushed into one of the O-ring-sealed ports (Swagelok 


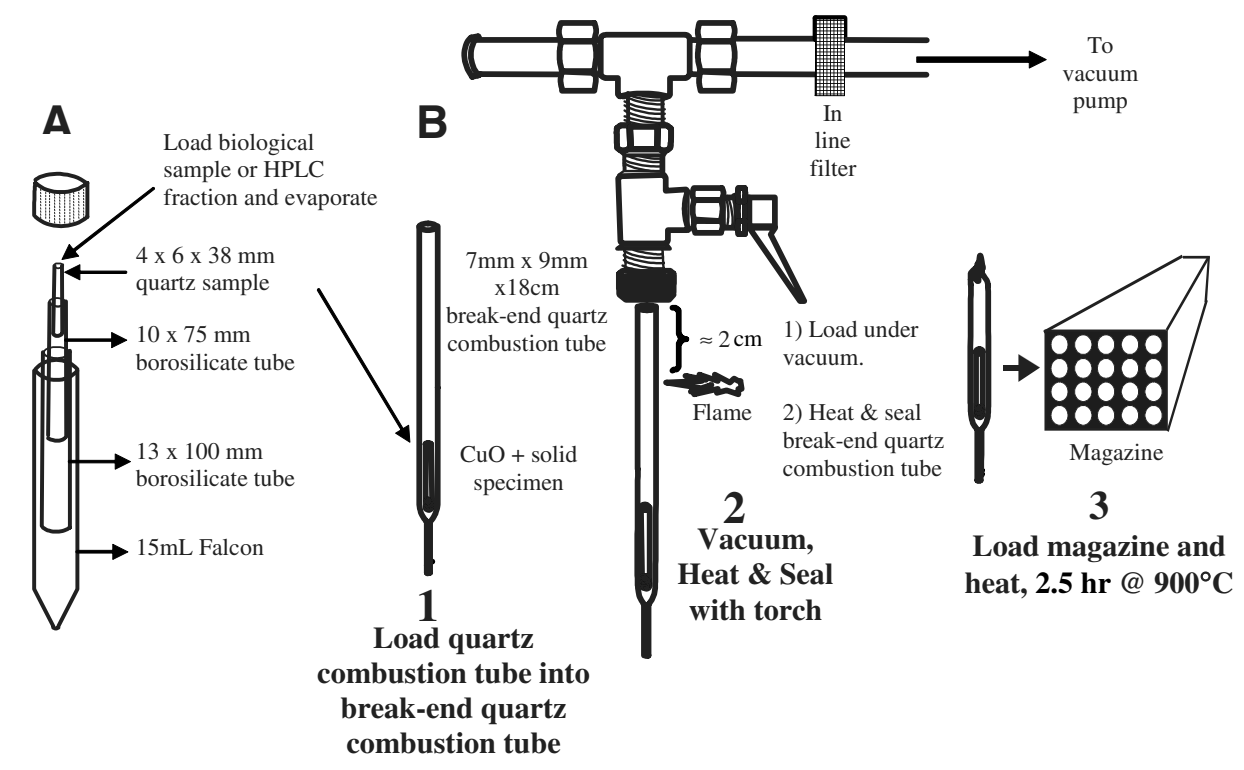

Figure 1 Converting sample carbon to $\mathrm{CO}_{2}$

Ultra-Torr, Solon, Ohio, USA) of the stainless steel vacuum manifold (Figure 1B). The vacuum valve is slowly opened, and the break-end quartz combustion tube is evacuated to $<10$ mTorr and then flame-sealed with a hydrogen or oxyacetylene torch.

\section{Combustion}

The flame-sealed 9-mm quartz combustion tubes are placed in a metal magazine containing 20 slots total (Figure 1B) and baked at $900{ }^{\circ} \mathrm{C}$ when using quartz sample tubes, and $650{ }^{\circ} \mathrm{C}$ when using borosilicate sample tubes for $2.5 \mathrm{hr}$ followed by a slow cooling back to room temperature within the oven. The magazine keeps the tubes in an ordered array and prevents destruction of multiple samples if one tube blows up due to an excess of sample material. The combustion reaction is shown below.

$$
\text { Dried biological sample }+\mathrm{CuO} \stackrel{900^{\circ} \mathrm{C}(2.5 \mathrm{hr})}{>} \mathrm{Cu}_{2} \mathrm{O} / \mathrm{Cu}+\mathrm{CO}_{2}+\mathrm{H}_{2} \mathrm{O}+\mathrm{N}_{2}+\mathrm{SO}_{2}+\ldots
$$

The adequacy of copper (II) oxide added to the 6-mm quartz or borosilicate sample tube can be checked by the presence of copper (II) oxide in the 6-mm quartz or borosilicate sample tube after combustion. Incomplete combustion is indicated when there is a complete lack of copper (II) oxide (black appearance) in the combusted sample.

During combustion, any volatile sodium that is generated migrates into the glass of the 9-mm breakend quartz combustion tube and will weaken or even decompose the quartz. Therefore, potassium buffer salts are used whenever possible when performing AMS experiments.

Samples with intrinsically high salt content, such as urine, may be combusted at lower temperatures $\left(500-650{ }^{\circ} \mathrm{C}\right)$ to reduce this destructive sodium migration into the 9-mm quartz combustion tube. These samples may also be aliquotted in 6-mm borosilicate glass sample tubes rather than the 6-mm 
quartz sample tubes when lower combustion temperatures are being used. Combusted samples may be stored for a few days before significant deterioration of $\mathrm{CO}_{2}$ to form copper carbonate occurs. If the combustion tubes are stored for longer periods, they need to be re-heated to $500{ }^{\circ} \mathrm{C}$ for $1 \mathrm{hr}$.

Samples containing 0.5-2 mg of carbon are ideal for making good graphite (Buchholz et al. 1999b; Vogel and Love 2005). However, this amount of sample is not always available in the isolated fraction, and tributyrin (glycerol tributanoate) is used as a source of supplemental carbon (carbon carrier) for carbon-poor samples $(<10 \mu \mathrm{g})$ due to its relatively low ${ }^{14} \mathrm{C}$, high carbon, low nitrogen, low vapor pressure, high solubility in alcohol, low toxicity, and good retention of volatile components (Buchholz et al. 1999b). However, tributyrin from different sources can differ in ${ }^{14} \mathrm{C}$ content (Table 2). Tributyrin with low ${ }^{14} \mathrm{C}$ is used to maintain a significant signal to background level, but the finite ${ }^{14} \mathrm{C}$ content provides an alert of unexpected ${ }^{14} \mathrm{C}$-depleted carbon in the collected sample (Vogel and Love 2005), which is not available from a ${ }^{14} \mathrm{C}$-free carrier. The difference in tributyrin ${ }^{14} \mathrm{C}$ levels between combustion in 6-mm quartz at $900{ }^{\circ} \mathrm{C}$ for $2.5 \mathrm{hr}(0.111 \pm 0.025 \mathrm{Mod})$ and 6-mm borosilicate glass at $650{ }^{\circ} \mathrm{C}$ for $2 \mathrm{hr}(0.118 \pm 0.024 \mathrm{Mod})$ is not significant.

Table 2 Comparison of tributyrins and benzoic acid for ${ }^{14} \mathrm{C}$ content measured by AMS.

\begin{tabular}{|c|c|c|c|}
\hline \multirow[b]{2}{*}{ Carbon sources } & \multirow[b]{2}{*}{$n$} & \multicolumn{2}{|c|}{${ }^{14} \mathrm{C}$ (fraction modern } \\
\hline & & Mean $^{\mathrm{a}}$ & Std. error \\
\hline Tributyrin, $\mathrm{MP}^{\mathrm{b}}$ & 10 & $0.018^{*}$ & 0.001 \\
\hline Tributyrin, LLNLc & 10 & $0.100^{\wedge}$ & 0.002 \\
\hline Tributyrin, Fluka ${ }^{\mathrm{d}}$ & 9 & $0.239 \bullet$ & 0.002 \\
\hline Benzoic acide $(2 \mathrm{mg})$ & 5 & $0.028^{\oplus}$ & 0.002 \\
\hline Benzoic $\operatorname{acid}^{\mathrm{e}}(2 \mu \mathrm{L})$ & 5 & $0.024^{\oplus}$ & 0.002 \\
\hline \multicolumn{4}{|c|}{$\begin{array}{l}{ }^{a} \text { Mean values with different superscripts are significantly different from one another } \\
(p<0.001) \text {. }\end{array}$} \\
\hline \multicolumn{4}{|c|}{ bMP Biomedicals, Solon, Ohio, USA (\#103111). } \\
\hline \multicolumn{4}{|c|}{$\begin{array}{l}\text { cTributryin obtained from LLNL (ICN Pharmaceuticals, Costa Mesa, California, USA). } \\
{ }^{\mathrm{d}} \text { Fluka, Chemical Corp., St. Louis, Missouri, USA (\#91010). } \\
\text { eFluka, Chemical Corp., see above (\#12353). }\end{array}$} \\
\hline
\end{tabular}

\section{Preparing Septa-sealed Vials}

The septa-sealed vial and gas transfer setup is shown in Figure 2 and is based on the procedures described by Ognibene et al. (2003). It consists of a septa-sealed vial (Pyrex, Kimax, or other generic borosilicate glass, $8 \mathrm{~mm}$ OD $\times 80 \mathrm{~mm} \mathrm{~L}$ ) and an inner vial (Pyrex, Kimax, or other generic borosilicate glass, $3.7 \mathrm{~mm} \mathrm{OD} \times 30 \mathrm{~mm} \mathrm{~L})$ as described in Table 1 . Three scoops $(\sim 100 \mathrm{mg})$ of zinc dust are added to the septa-sealed vial using a 3.5-mm curette (Miltex Instruments, Chalazion Curette \#18-506, Bangor, Maine, USA) followed by 4 glass beads $(3 \mathrm{~mm}$ ) that are dropped atop the zinc dust. About $10 \mathrm{mg}$ of spherical iron powder is added to the inner vial using a 2-mm curette (Chalazion Curette \#18-502) that is then placed atop the glass beads. The glass beads keep the inner vial separated from the zinc dust. The septa-sealed vial is then crimp-sealed. Large numbers of the septa-sealed vials may be assembled and stored upright for several weeks prior to use.

\section{Gas Transfer}

After the biological sample is combusted to $\mathrm{CO}_{2}$ gas, the gas must be transferred to the septa-sealed vial. This is done by connecting the break-end quartz combustion tube to a gas transferring appara- 


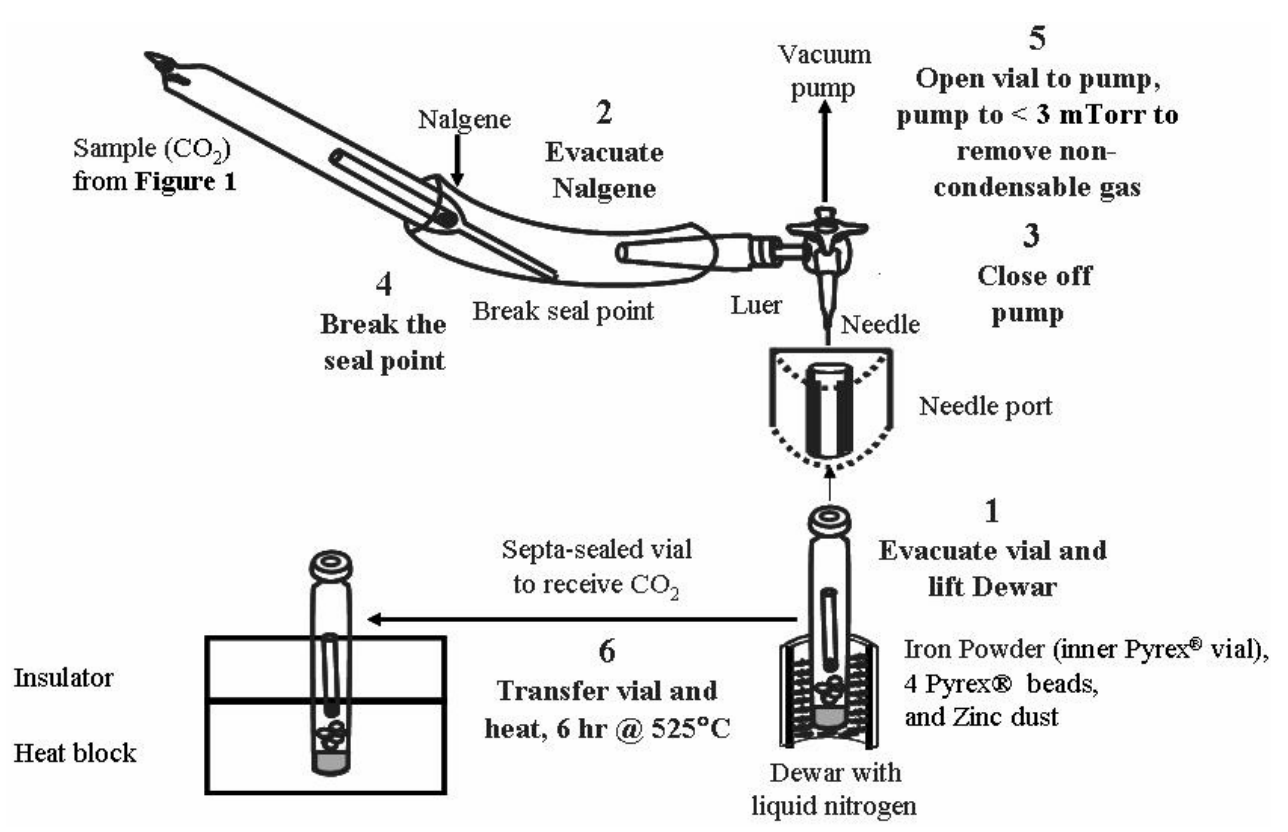

Figure 2 Transferring $\mathrm{CO}_{2}$ gas to septa-sealed vial and reduction to graphite

tus (Figure 2). The apparatus consists of the break-end quartz combustion tube connected to 7.2-cmlong Nalgene tubing (5/16" ID $\times 1 / 2$ " OD), which is connected to a disposable 4-way stopcock via a male luer. Next, the loaded septa-sealed vial is inserted into the base of the needle port. Once inserted, the loaded septa-sealed vial is connected to a second arm of the 4-way stopcock by a 26gauge, $3 / 8$-inch long needle ( $\left.26 \mathrm{G}^{\prime \prime}\right)$. The third arm of the stopcock is connected to a vacuum pump with a vacuum gauge controller (Table 1, Figure 2).

The Nalgene tube connecting the break-end quartz combustion tube to the male luer is evacuated first to $<3$ mTorr. The septa-sealed vial is then evacuated to $<3$ mTorr. A Dewar flask containing liquid nitrogen is placed below the septa-sealed vial and raised just above the level of zinc dust using a laboratory jack. The top port of the 4-way stopcock is closed to the vacuum pump and opened to connect the 9-mm quartz combustion tube to the septa-sealed vial. The break seal is snapped to allow transfer of $\mathrm{CO}_{2}$ from the 9-mm quartz combustion tube to the septa-sealed vial. The $\mathrm{CO}_{2}$ gas is cryogenically trapped in the septa-sealed vial, and 2 white bands of frozen condensable products (mostly $\mathrm{CO}_{2}$ and $\mathrm{H}_{2} \mathrm{O}$ ) will appear at the top of the liquid nitrogen contact. The combustion products of samples that produce large amounts of nitrogen or other non-condensable gasses must be carefully handled since the uncondensable gasses warm the inner surface of the condensate to a temperature at which the $\mathrm{CO}_{2}$ no longer solidifies. A new condensing surface is created by raising the liquid nitrogen level by a few $\mathrm{mm}$, which usually produces another condensation ring. When transferring nitrogen-rich biological samples (e.g. urine or protein extractions), this process of raising the liquid nitrogen level a few $\mathrm{mm}$ at a time is repeated until space precludes it or until no new condensation rings appear. Non-condensable products in the septa-sealed vial are then removed by re-opening the top port of the 4-way stopcock to the vacuum pump. The entire transfer process takes 1 min for simple samples. After gas transfer is complete, the septa-sealed vial is removed from the needle port of the 4-way stopcock and labeled, and its $\mathrm{CO}_{2}$ is ready for reduction to graphite. 


\section{Reducing $\mathrm{CO}_{2}$ to Graphite}

The septa-sealed vial containing $\mathrm{CO}_{2}$ is placed in a heating block at $525{ }^{\circ} \mathrm{C}$ for $6 \mathrm{hr}$ (Figure 2). The reaction is only mildly sensitive to temperature, with quantitative yields occurring at $450-650{ }^{\circ} \mathrm{C}$ (Vogel et al. 1984, 1987; Vogel 1992; McNichol et al. 1992). The reaction temperature is not critical, but it must be well controlled at or below the glass softening temperature. The septa-sealed vials (melting point: $820^{\circ} \mathrm{C}$ ) will soften within the heater holes at temperatures above $600{ }^{\circ} \mathrm{C}$ and can be difficult to remove from the heating block. The septa-sealed vial may be left in the slowly cooling heater block if a timer is set to turn off the heater for ease of "overnight" reductions. The $\mathrm{CO}_{2}$ is reduced to graphite that coats the iron catalyst within the septa-sealed inner vial. The chemical reactions that occur during reduction of $\mathrm{CO}_{2}$ to graphite are shown below.

$$
\begin{aligned}
& \mathrm{CO}_{2}+\mathrm{Zn} \rightarrow \mathrm{CO}+\mathrm{ZnO} \\
& \mathrm{H}_{2} \mathrm{O}+\mathrm{Zn} \rightarrow \mathrm{H}_{2}+\mathrm{ZnO} \\
& \mathrm{CO}+\mathrm{H}_{2} \stackrel{\text { Fe catalyst }}{ } \longrightarrow \text { Graphite }+\mathrm{H}_{2} \mathrm{O}
\end{aligned}
$$

Water produced from the combustion process is reduced to form the hydrogen required to drive the graphite production. Therefore, the $\mathrm{CO}_{2}$ produced in the combustion is not "dried" to remove water vapor. Sulfur compounds are quickly reduced to zinc sulfide, removing an important poison of the iron catalytic reaction. Any non-condensable nitrogen remaining in the septa-sealed vial is inert to these reactants. The resultant graphite is highly absorptive of volatile organic vapors (Buchholz et al. 2000), and the cooled, septa-sealed vials are the best storage option for the prepared graphite sample until it is pressed/tamped/hammered/packed into the AMS sample holder.

\section{Loading Graphite into the AMS Sample Holders}

AMS sample holders and the procedures used to load them are AMS-instrument specific. The procedure for loading graphitized samples into AMS sample holder for the Lawrence Livermore National Laboratory (LLNL) is shown in Figure 3. The graphite-coated iron is removed from the septa-sealed vial by "decapping" the septa seal. The graphite-coated iron is poured into a conical depression that surrounds the 2.5 -mm-deep, 1.32-mm-diameter hole drilled into the $9.5 \times 29-\mathrm{mm}$ cylindrical aluminum sample holder provided by LLNL's AMS group. A mini-Plexiglas ${ }^{\circledR}$ hood $(2 \times$ $1 \mathrm{ft}$ ) connected to a low vacuum is used to reduce powder dispersion and prevent sample contamination while loading the graphite into the AMS sample holder. The graphite sample is pressed/ tamped/hammered/packed into the hole with a new \#55-gauge drill blank cleaned with emery paper (Table 1, Figure 3). The final graphite surface should be $\geq 1 \mathrm{~mm}$ from the top of the hole. It is not always possible to transfer all of the graphitized sample into the AMS sample holder. The LLNL ion source performance is independent of the packing pressure, but sufficient pressing/tamping/hammering/packing is important for the sample to stay in the AMS sample holder during shipping and handling. The AMS sample holders are then packed and shipped to LLNL for measuring ${ }^{14} \mathrm{C}$ using AMS. The ${ }^{14} \mathrm{C} /{ }^{13} \mathrm{C}$ ratios measured experimentally are normalized to measurement standards of known ${ }^{14} \mathrm{C}$ concentration (e.g. Australian National University sucrose, ANU) (Vogel and Love 2005).

\section{Results}

We used these AMS procedures to increase fundamental knowledge of the basic biochemistries of folate and carotenoid metabolism. Sample data sets from these studies are shown in Figures 4 to 6 . 


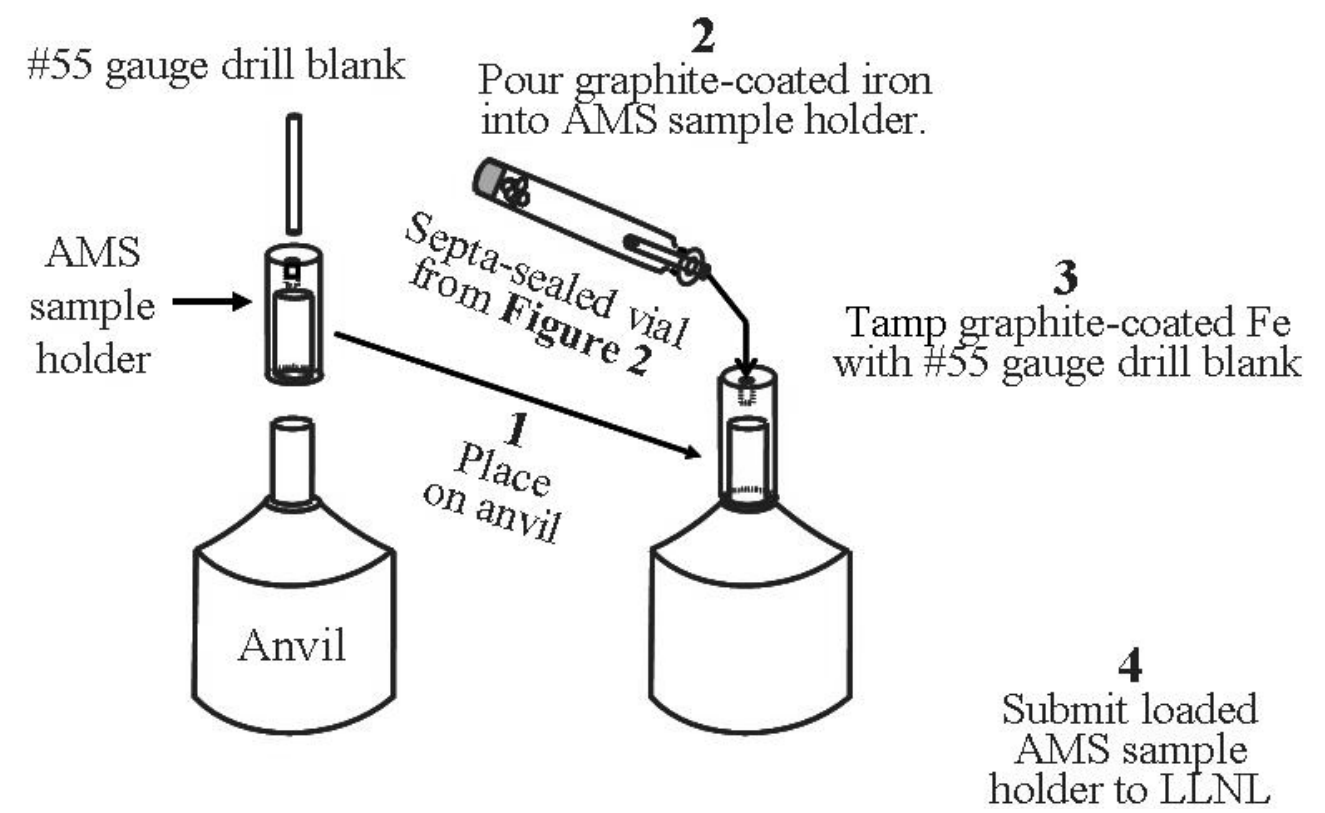

Figure 3 Loading AMS sample holder with graphite-coated iron

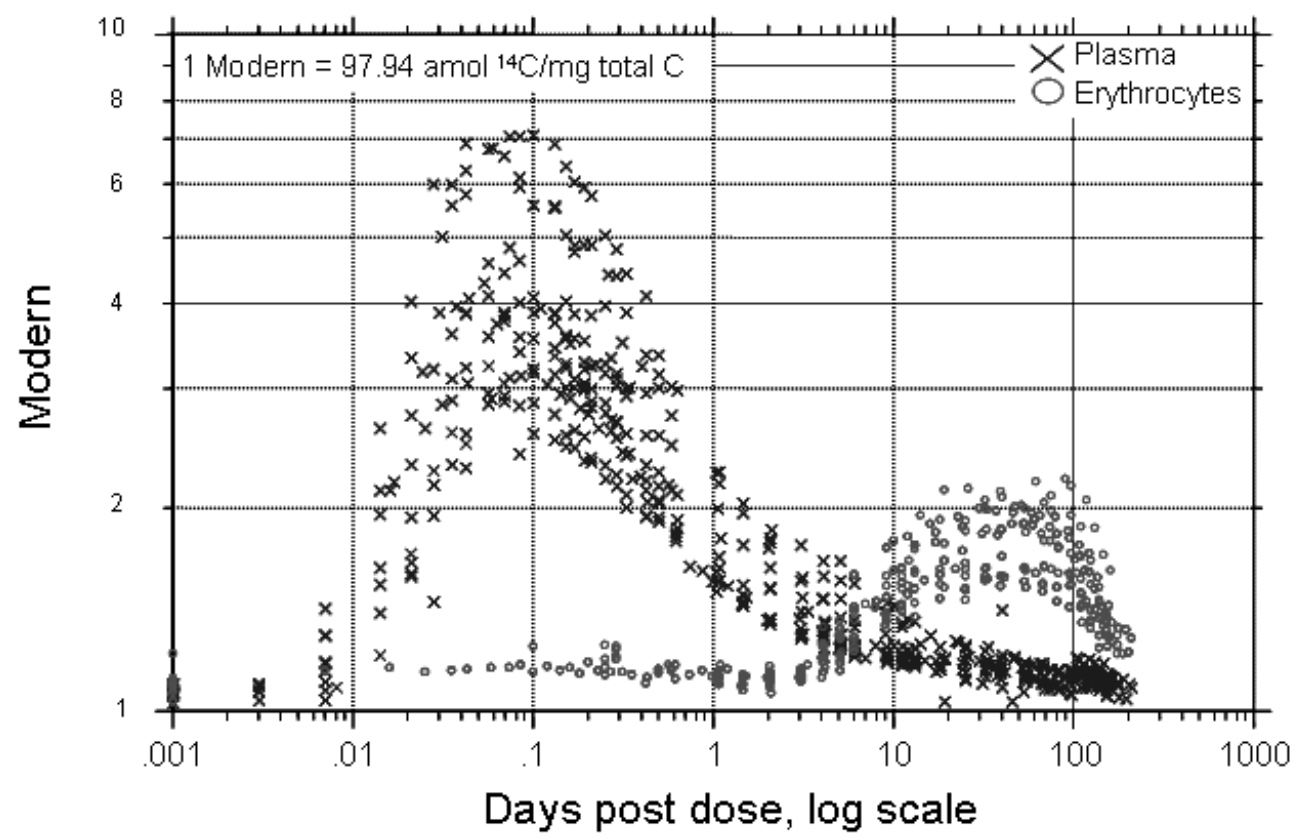

Figure 4 Ratio of ${ }^{14} \mathrm{C}$ to total carbon in plasma and erythrocytes of an adult human by time since administration of a very small oral dose of ${ }^{14} \mathrm{C}$-folic acid.

Folate functions as a cofactor in the transfer and utilization of 1-carbon groups. AMS was used to study the metabolism of small tracer oral doses of ${ }^{14} \mathrm{C}$ pteroylmonoglutamate (a form of folate) in plasma, erythrocytes (RBC) from blood drawn over a 202-d period, and in urine and feces collected over a 44-d period from a healthy human volunteer (Buchholz et al. 1999a). This study indicated 


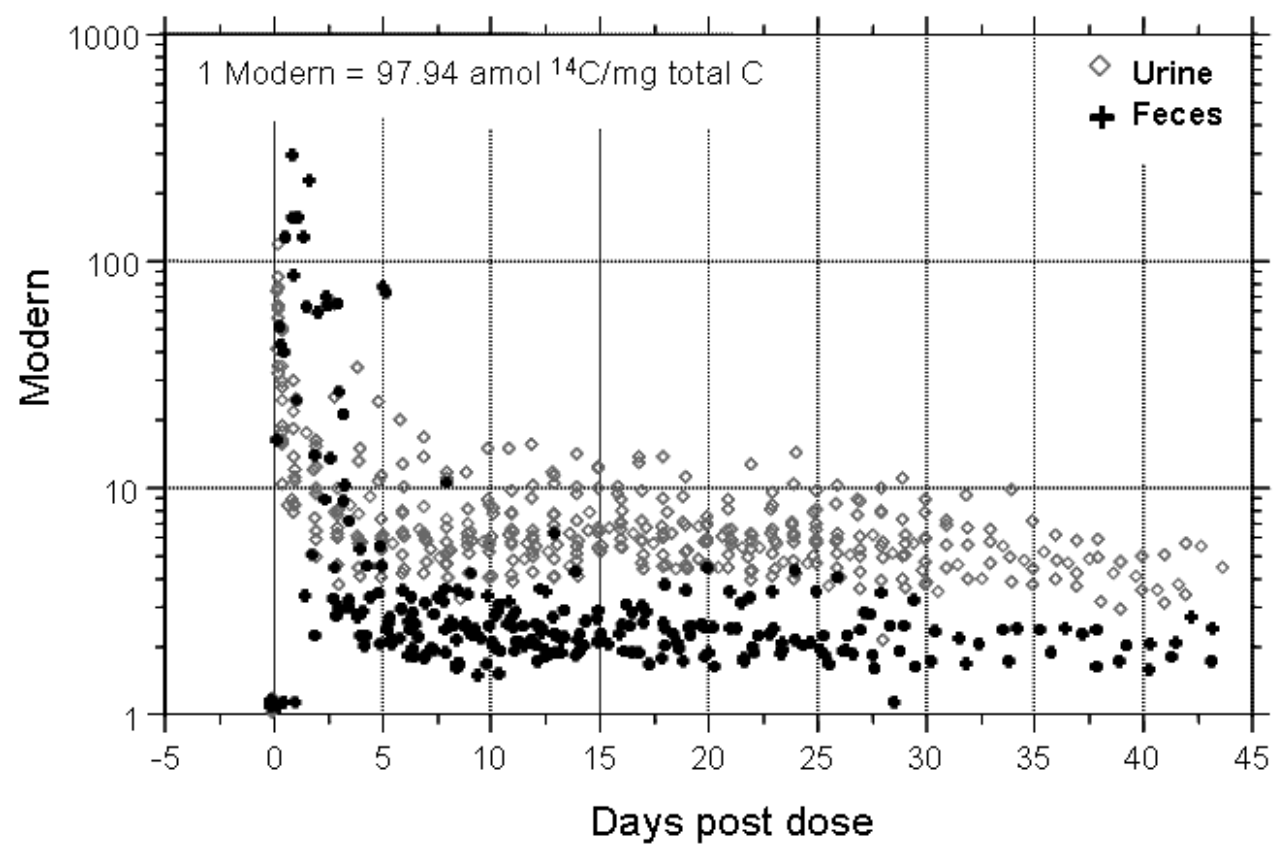

Figure 5 Ratio of ${ }^{14} \mathrm{C}$ to total carbon in urine and feces of an adult human by time since administration of a very small oral dose of ${ }^{14} \mathrm{C}$-folic acid.

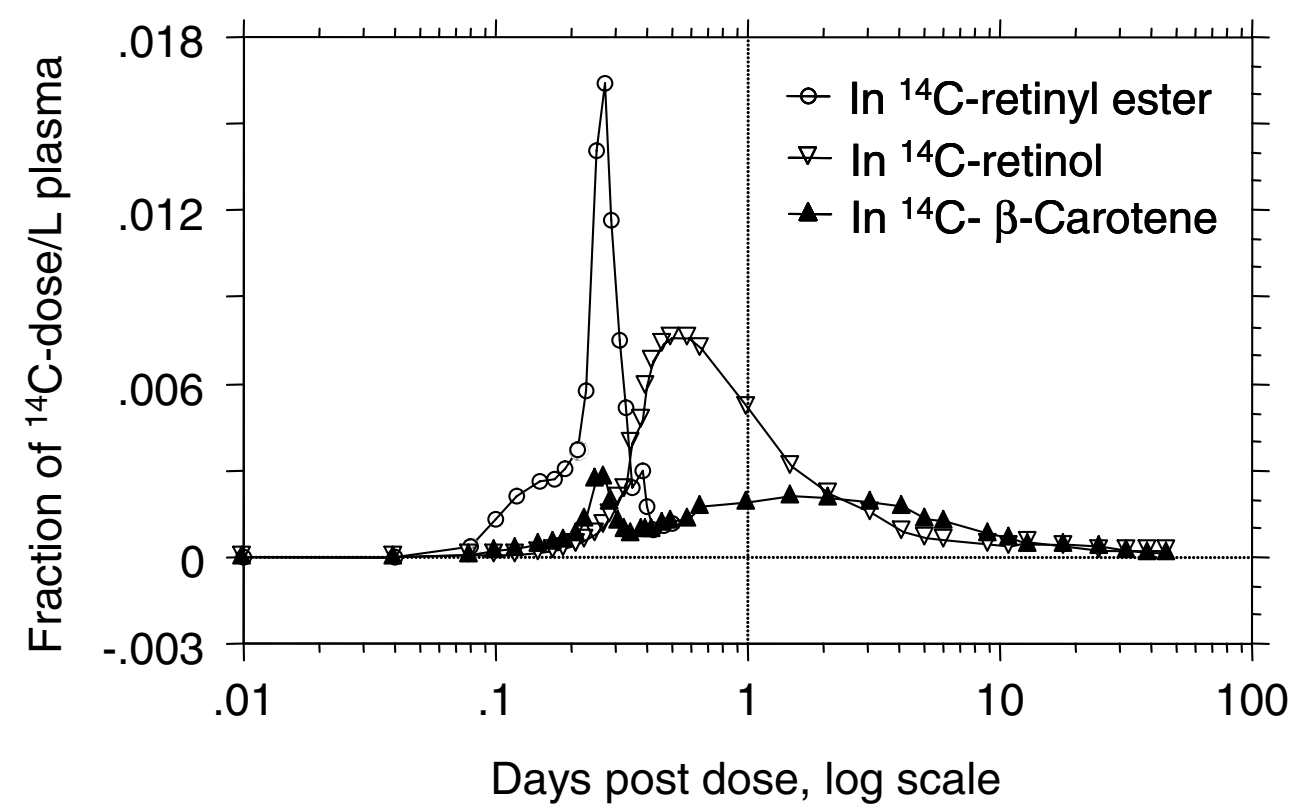

Figure 6 Fraction of an administration of a dose of ${ }^{14} \mathrm{C}$ - $\beta$-carotene that appears in plasma ${ }^{14} \mathrm{C}$-retinyl ester, ${ }^{14} \mathrm{C}$-retinol, and ${ }^{14} \mathrm{C}-\beta$-carotene as a function of time since dosing. 
that $90 \%$ of the dose was absorbed and more than $75 \%$ was retained in the body after $42 \mathrm{~d}$. In another study, AMS was used to assess the kinetics of folate metabolism from oral dose of $\left[{ }^{14} \mathrm{C}\right]$ pteroylmonoglutamate in 13 human volunteers (Lin et al. 2004). Figure 4 shows the trace of folate in the erythrocytes, and Figure 5 shows the elimination of the ${ }^{14} \mathrm{C}$ tracer in the urine and feces. Figures 4 to 6 show some characteristic difficulties and advantages associated with nutritional and biological samples. Specifically, the scientist must work with a large series of similar, relatively homogenous samples to obtain useful data, but the samples are good candidates for batch processing, automation, and, potentially, direct injection of combustion $\mathrm{CO}_{2}$ into a gas-accepting ion source (Liberman et al. 2004). The results from these studies were used to construct a kinetic model of folate metabolism, which indicated that the absorbed fraction of the administered dose ranged from 65 to $97 \%$ with mean value of $79 \%$, and there was no correlation between fractional absorption and intake of folate. Understanding the extent of bioavailability of folate that can be achieved by radioisotope measurement using AMS is key to establishing intake levels for optimal health.

We conducted similar studies with $\beta$-carotene, one of a large group of pigments known as carotenoids, some of which serve as metabolic precursors to vitamin A. The benefits of B-carotene to health may extend well beyond its function as a vitamin A source, although there have been contradictory reports on the health benefits of $B$-carotene. The nutritional and chemo-preventive role played by $\beta$-carotene is not well understood due to the complexity in its absorption, transport across tissues, and its subsequent metabolism. We administered ${ }^{14} \mathrm{C}$-labeled $\mathrm{B}$-carotene to an adult human subject and determined its half-life in blood, its bioavailability, and its bioconversion to vitamin A (Dueker et al. 2000). Figure 6 shows the parent compound and its metabolites in plasma by time since dose; the ability to trace the ${ }^{14} \mathrm{C}$ parent and ${ }^{14} \mathrm{C}$ metabolites (even if chemical identity is unknown) is a major advantage of AMS. We determined that $\sim 43 \%$ of the dosed $\beta$-carotene was absorbed in the first 48-hr collection period and that $1 \mathrm{~mol} \mathrm{B-carotene} \mathrm{converted} \mathrm{to} 0.6 \mathrm{~mol}$ of vitamin A. After vitamin A supplementation, higher absorption resulted in larger molar vitamin A values (Lemke et al. 2003).

\section{DISCUSSION}

Quantifying the ${ }^{14} \mathrm{C}$ content of biological samples is a 2-step process. Step 1 is to convert sample carbon to a form compatible with the AMS ion source, graphite for most AMS spectrometers, and step 2 is to obtain the isotope ratio of that prepared material normalized to similarly prepared known isotopic standards using AMS. These steps are operationally easily separated, so a remote AMS can easily serve scattered research groups that correctly reduce their samples to the particular form required for AMS measurement.

AMS has been specifically designed to measure ${ }^{14} \mathrm{C}$ with the exclusion of potential molecular and isobaric interferences through energetic collisions followed by momentum and mass spectrometries. The final ion detector can identify charge and mass of the incident ions to further resolve specific isotopic ions. The complete discrimination against ${ }^{14} \mathrm{~N}$ (the nuclear isobar of ${ }^{14} \mathrm{C}$ ) through negative ionization (Buckman and Clark 1994) reduces the task of the spectrometer to that of complete destruction and ion separation of molecular isobars, primarily ${ }^{12} \mathrm{CH}_{2}$ and ${ }^{13} \mathrm{CH}$, allowing for the development of the spectrometers that operate at lower acceleration energies (200-500 kV). The high selectivity of AMS spectrometers thus dictates that the sample preparation deliver quantitative, uncontaminated, consistent samples that produce high ion outputs, usually graphite-coated on an iron catalyst/binder powder. The procedures listed here have produced many thousands of samples for the study of human metabolism and transport of essential, low-dose vitamins. 


\section{CONCLUSION}

AMS is an exceptionally powerful tool for metabolic research, but the growth of AMS as a research tool has been limited because AMS sample preparation methods require attention to details that prevent contamination in a tracing laboratory. There is a dearth of educational opportunities and training tools for teaching AMS methods to new investigators. We provide detailed descriptions and diagrams of our sample preparation procedures for converting fecal, urine, blood, or other biological samples to graphite for AMS. Further advances in AMS sample preparation methods and more collaboration between end-users and AMS providers are needed and should result in more widespread and more cost-effective usage of this powerful technique.

\section{ACKNOWLEDGMENTS}

This work was performed in part under the auspices of the U.S. Department of Energy by the University of California-Lawrence Livermore National Laboratory under Contract W-7405-Eng-48. This work was supported by NIH National Center for Research Resources Grant RR13461, National Institute of Environmental Health Sciences (NIEHS) Superfund Basic Research Program Grant P42 ES04699, NIH DK 45939, and Grant/Cooperative Agreement (RO1 8928) from the Centers for Disease Control and Prevention.

\section{REFERENCES}

Buchholz BA, Arjoumand A, Dueker SR, Clifford AJ, Vogel JS. 1999a. Intrinsic erythrocyte labeling and attomole pharmacokinetic tracing of ${ }^{14} \mathrm{C}$-folic acid with accelerator mass spectrometry. Analytical Biochemistry 269:348-52.

Buchholz BA, Fultz E, Haack KW, Vogel JS, Gilman SD, Gee SJ, Hammock BD, Hui X, Wester RG, Maibach HI. 1999b. HPLC-accelerator MS measurement of atrazine metabolites in human urine after dermal exposure. Analytical Chemistry 71(16):3519-25.

Buchholz BA, Freeman SP, Haack KW, Vogel JS. 2000. Tips and traps in the C-14 bio-AMS preparation laboratory. Nuclear Instruments and Methods in Physics Research B 172(1-4):404-8.

Buckman SJ, Clark CW. 1994. Atomic negative ion resonances. Reviews of Modern Physics 66:539-55.

Dueker SR, Lin Y, Buchholz BA, Schneider PD, Lame MW, Segall HJ, Vogel JS, Clifford AJ. 2000. Longterm kinetic study of $\beta$-carotene, using accelerator mass spectrometry in an adult volunteer. Journal of Lipid Research 41:1790-800.

Kutschera W. 2005. Progress in isotope analysis at ultratrace level by AMS. International Journal of Mass Spectrometry 242:145-60.

Lemke SL, Dueker SR, Follett JR, Lin Y, Carkeet C, Buchholz BA, Vogel JS, Clifford AJ. 2003. Absorption and retinol equivalence of $\beta$-carotene in humans is influenced by dietary vitamin A intake. Journal of Lipid Research 44:1591-600.

Liberman RG, Tannenbaum SR, Hughey BJ, Shefer RE, Klinkowstein RE, Prakash C, Harriman SP, Skipper
PL. 2004. An interface for direct analysis of ${ }^{14} \mathrm{C}$ in non-volatile samples by accelerator mass spectrometry. Analytical Chemistry 76(2):328-34.

Lin Y, Dueker SR, Follett JR, Fadel JG, Arjomand A, Schneider PD, Miller JW, Green R, Buchholz BA, Vogel JS, Phair R, Clifford AJ. 2004. Quantitation of in vivo human folate metabolism. American Journal of Clinical Nutrition 80:680-91.

McNichol AP, Gagnon AR, Jones GA, Osborne EA. 1992. Illumination of a black box: analysis of gas composition during graphite target preparation. $R a$ diocarbon 34(3):321-9.

Ognibene TJ, Bench G, Vogel JS, Peaslee GF, Murov S. 2003. A high-throughput method for the conversion of $\mathrm{CO}_{2}$ obtained from biomedical samples to graphite in septa-sealed vials for quantification of ${ }^{14} \mathrm{C}$ via accelerator mass spectrometry. Analytical Chemistry 75(9): 2192-6.

Vogel JS. 1992. Rapid production of graphite without contamination for biomedical AMS. Radiocarbon 34(3):344-50.

Vogel JS, Love A. 2005. Quantitating isotopic molecular labels with AMS. In: Burlingame AL, editor. Methods in Enzymology. New York: Academic Press. p 402-23.

Vogel JS, Southon JR, Nelson DE, Brown TA. 1984. Performance of catalytically condensed carbon for use in accelerator mass spectrometry. Nuclear Instruments and Methods in Physics Research B 5(2):289-93.

Vogel JS, Nelson DE, Southon JR. 1987. Background levels in an AMS system. Radiocarbon 29(2):215-22. 